\title{
Factors affecting operating time in resection of Rectal Cancer
}

\author{
Mudasir Sofi M.S., , Fazl Q Parray M.S., ${ }^{2}$ Feroze Shaheen M.D., ${ }^{3}$ Nisar A Chowdri M.S., ${ }^{4}$ \\ Rauf A Wani M.S. ${ }^{5}$ \\ 1,2,5 Post Graduate scholar,Professor, Additional Professor, Colorectal Division, SKIMS \\ ${ }^{3}$ Professor Department of Radiodiagnosis, SKIMS, ${ }^{4}$ Prof. General and Minimal Invasive Surgery
}

\section{A B S T R A C T}

\begin{abstract}
Back ground: - Rectal cancer continues to be a challenging disease which most of the time needs proper staging and multimodal management to achieve the best possible cure rates. For operating surgeons many factors may play a role in predicting the technical difficulties while conducting the operation.

Objective : Objective of this study is to understand the relationship between Age, body mass index (BMI),Gender and patients anatomical factors on operating time in resection of mid low rectal cancer.

Methods: This was a prospective observational study conducted over a period of two years from Sept 2015 to Sept 2017. The study was conducted in the department of General and Minimal Invasive Surgery, SKIMS which included 29 patients with mid-lower rectal cancer, who underwent anterior resection. Demographic data, body mass index (BMI), distance of tumor from anal verge and pelvimetry measurements were collected and analyzed with respect to operating time using co- relation coefficient analysis, principal component analysis, and linear regression.

Results: The study included 20 (68.96\%) females and 9 (31.03\%) males. The mean operating time was $136.72 \pm 30.09$. Multivariate analysis showed that parameters such as $B M I(P=0.05)$, anatomical transverse distance $(I P)(P=0.000)$, interischial distance $(I S)(0.004)$, intertuberous distance (IT) $(P=0.003)$, angle 5 (the angle of the lower border of symphysis pubis to the upper border of symphysis pubis to the sacral promontory) $(p=0.017)$ and distance of tumor from anal verge $(T d)(p=0.001)$, were statistically significant. Whereas parameters such as Interacetabular distance $(I A)(P=0.11)$ and distance from Pubis to coccyx $(C O S Y)(P=0.674)$ had no statistical significance.

Conclusion: Gender, BMI, angle 5, tumor distance from anal verge, transverse diameters of the pelvis except IA, and COSY played the most important role in affecting operating time. The equation can be very useful tool for pre-operative assessment. JMS 2018:21 (2):77-83
\end{abstract}

\section{INTRODUCTION}

Colorectal cancer is one of the common malignancies and a leading cause of cancer death in U.S. and worldwide. ${ }_{-}^{[1,2]}$ Rectal cancer is on the rise in the valley of Kashmir; however the incidence of colorectal cancer in Kashmir is similar to that reported in the rest of India. ${ }^{[3]}$ Since, we are working in a tertiary care hospital, catering to a population of more than 10 million in the sub-specialty of colorectal division; we get exposed to more volume of rectal cancer when compared with most of the centers in and outside the country. Because of increasing trend in rectal cancers in this part of world, different studies have been conducted with a view to assess the surgical outcome, complications and technical difficulties encountered while performing a sphincter preserving surgery ${ }^{[4]}$. Surgical resection is

\section{Correspondence}

Dr. Fazl Q Parray

Professor, Colorectal Division, SKIMS, Srinagar

Email: fazlparray@rediffmail.com considered a standard of treatment for patients with nonmetastatic colorectal cancer which can be performed either by open or laparoscopic technique. Laparoscopic resection has similar short and long term outcomes as conventional open surgery, ${ }^{[5-8]}$ but with more clinical advantages. ${ }^{[5,9]}$

For analysing the factors affecting operative difficulty, operating time is usually chosen as the primary measure of difficulty as it is objective and well suited to a relatively small sample size in which some operative complications may not occur ${ }^{[10-11]}$ Pelvimetry and tumor characteristics are expected to be other factors responsible for predicting the operative difficulty. Some factors that have been shown to be associated with operative time and hence difficulty are high body mass index (BMI), narrow pelvic outlet, tumors closer to the anal verge, tumor stage, previous abdominal surgery, and preoperative radiotherapy. ${ }^{[10-13]}$ A deep and narrow pelvis in some patients and the effects of neoadjuvant chemo-radiation treatment make the operation more demanding. Moreover, there is the need to minimise injury to autonomic nerves that are responsible for postoperative urinary and sexual function. ${ }^{[11,14-20]}$ 
$\mathrm{CT}$ and magnetic resonance imaging (MRI) pelvimetry have been coming back into vogue for a lower rectal cancer with or without radiation dose. CT and MRI pelvimetry are also an accurate and reliable technique for obtaining pelvimetric measurements, which have been utilized for patients with rectal cancer. Costs of MRI pelvimetry are obviously greater than those of CT techniques. Finally, financial considerations limit the clinical usage of MRI. Therefore, CT pelvimetry is widely used in patients with rectal cancer because of its relatively inexpensive costs and convenience. ${ }^{[21]}$

\section{METHODS}

A prospective and observational study was performed in mid low rectal cancer patients from September 2015 to September 2017. The study was conducted in the department of General and Minimal Invasive Surgery, SKIMS. Patients with a tumor located $4-12 \mathrm{~cm}$ from anal verge and histologically proven adenocarcinomas were included in the study. All other patients subjected to emergency surgery, patients with a history of additional surgeries in addition to rectal cancer surgery and patients who received neo-adjuvant chemo radiotherapy (NACRT) were excluded from the study.

The study patients were evaluated as per hospital protocol. Preoperative data, including demographic characteristics, history of preoperative neo-adjuvant chemo-radiotherapy (NACRT), history of lower abdominal surgery, BMI, and distance of the tumor from the anal verge (Td), were reviewed from the patient's medical records. Computed tomographic (CT) pelvimetery measurements (table 1) were taken by a same consultant Radiologist and noted down. Operative time was calculated from the electronic record on the anesthesia machine from the start of making a skin incision till the closure of abdominal wound or port site.

\section{Statistical analysis:}

Statistical analysis of data were performed using STATA software. Descriptive analyses were used to characterize the study population. We defined Operating time as dependent variable and patient's demographic and pelvic anatomical diameters as independent variables. All statistically significant factors by univariate analysis were then used in multivariate analysis. Pearson's correlation coefficient was used to determine the relationship between factors and operating time. Linear regression was applied for data correlated with operating time. If collinearity existed, principle components analysis was applied to further explore the internal relationship between factors and operating time. A $p$ valve of less than 0.05 was considered significant.

\section{RESULTS}

A total of 29 patients were studied which included,20 $(68.96 \%)$ females and $9(31.03 \%)$ males. The mean operating time was $136.72 \pm 30.09$ minutes (table 2). Males had longer operating time than females by about 4 minutes which was statistically significant (p 0.001);overall pelvic diameters in females were larger than males (table 3).Univariate analysis showed that BMI $(\mathrm{p}=0.0000)$, interacetabular distance ( IA) $(\mathrm{p}=0.0001)$, Anatomical transverse distance(IP) $(\mathrm{p}=0.020)$, Interischial distance(IS) $(\mathrm{p}=0.0000)$ intertuberous distance $(\mathrm{IT})(\mathrm{p}=0.0000)$, Pubis to coccyx distance $(\mathrm{COSY})(\mathrm{p}=0.0000)$, the angle of the lower border of symphysis pubis to the upper border of the symphysis pubis to the sacral promontory(Angle 5) $(p=0.0004)$, distance of tumor from anal verge $(\mathrm{Td}$ )$(\mathrm{p}=0.0000)$ correlated with operating time .However multivariate analysis showed that BMI $(\mathrm{P}=0.05)$, IP $(\mathrm{P}=0.000)$, IS (0.004), IT $(\mathrm{P}=0.003)$, Angle $5(\mathrm{p}=0.017)$ and $\mathrm{Td}(\mathrm{p}=0.001)$, were statistically significant, while as IA $(\mathrm{P}=0.11)$ and $\operatorname{COSY}(\mathrm{P}=0.674)$ had no statistical significance.

Table 1: Pelvimetry measurements used by consultant radiologist

\begin{tabular}{|c|c|}
\hline Measurement & Definition \\
\hline Interacetabular distance (IA) & Distance between the most inner points of right and left femoral heads \\
\hline Anatomical transverse distance (IP) & $\begin{array}{l}\text { Distance between the most outer points of right and left iliopectineal } \\
\text { lines }\end{array}$ \\
\hline Interischial distance (IS) & Distance between the right and left ischial spines \\
\hline Intertuberous distance (IT) & $\begin{array}{l}\text { Distance between the most inner points of right and left ischial } \\
\text { tuberosities }\end{array}$ \\
\hline Pubis to coccyx (Cosy) & Distance from the lower border of symphysis pubis to the tip of coccyx \\
\hline Angle 5 & $\begin{array}{l}\text { The angle of the lower border of symphysis pubis to the upper border of } \\
\text { symphysis pubis to the sacral promontory }\end{array}$ \\
\hline \multirow[t]{2}{*}{ BMI(body mass index) } & weight in $\mathrm{Kg}$ \\
\hline & Height in meter ${ }^{2}$ \\
\hline
\end{tabular}


Table 2 :Operating time correlation to pelvimetry

\begin{tabular}{|l|l|l|l|l|l|}
\hline Variable & $\begin{array}{l}\text { Number of } \\
\text { patients }\end{array}$ & Mean & $\begin{array}{l}\text { Standard } \\
\text { deviation }\end{array}$ & Min & Max \\
\hline Operation time (OT) (Minutes) & 29 & 136.7241 & 30.09734 & 90 & 200 \\
\hline BMI & 29 & 24.98069 & 3.231005 & 21.1 & 33.8 \\
\hline IA & 29 & 12.50897 & 0.9768256 & 11.1 & 14.4 \\
\hline $\boldsymbol{I P}$ & 29 & 13.6069 & 1.439477 & 11.1 & 16.7 \\
\hline $\boldsymbol{I S}$ & 29 & 12.30345 & 0.7688037 & 9.9 & 13.1 \\
\hline $\boldsymbol{I T}$ & 29 & 11.7569 & 1.492584 & 8.9 & 13.5 \\
\hline COSY & 29 & 11.02069 & 0.9685701 & 8.5 & 12.1 \\
\hline Angle 5 & 29 & 23.62069 & 2.651331 & 20 & 28 \\
\hline Distance from anal verge(in cm) (Td) & 29 & 6.448276 & 1.205233 & 4 & 8 \\
\hline
\end{tabular}

Table 3 : Statistical significance of pelvimetry measurements

\begin{tabular}{|l|l|l|l|}
\hline Variables & Mean( males) & Mean (females) & P valve \\
\hline OT & $137.75 \pm 25.82$ & $134.444 \pm 39.72$ & 0.001 \\
\hline BMI & $23.99778 \pm 2.96$ & $25.425 \pm 3.33$ & 0.002 \\
\hline IA & $12.23333 \pm 1.212$ & $12.633 \pm 0.857$ & 0.006 \\
\hline IP & $13.12222 \pm 1.300$ & $13.825 \pm 1.47$ & 0.010 \\
\hline IS & $12.1778 \pm 0.916$ & $12.36 \pm 0.712$ & 0.001 \\
\hline IT & $11.6725 \pm 1.57$ & $11.94444 \pm 1.377$ & 0.003 \\
\hline COSY & $10.67 \pm 0.949$ & $11.13333 \pm 1.059$ & 0.092 \\
\hline Angle 5 & $24.11111 \pm 2.571$ & $23.4 \pm 2.72$ & 0.06 \\
\hline Td & $6.666667 \pm 1.479$ & $6035 \pm 1.089$ & 0.10 \\
\hline
\end{tabular}

Table 4: Correlation coefficient of pelvimetry measurements

\begin{tabular}{|l|l|l|l|l|l|l|l|l|l|}
\hline & OT & BMI & IA & IP & IS & IT & COSY & Angle 5 & Td \\
\hline OT & 1.0000 & & & & & & & & \\
\hline BMI & 0.7759 & 1.0000 & & & & & & & \\
& 0.0000 & & & & & & & & \\
\hline IA & -0.6498 & -0.2631 & 1.0000 & & & & & & \\
& 0.0001 & 0.1678 & & & & & & & \\
\hline IP & -0.2410 & 0.0353 & 0.2996 & 1.0000 & & & & & \\
& 0.2079 & 0.8556 & 0.1144 & & & & & & \\
\hline IS & -0.8746 & -0.7800 & 0.4892 & 0.2849 & 1.0000 & & & & \\
& 0.0000 & 0.0000 & 0.0071 & 0.1341 & & & & & \\
\hline IT & -0.8438 & -0.7965 & 0.4566 & -0.1672 & 0.7040 & 1.0000 & & & \\
& 0.0000 & 0.0000 & 0.0128 & 0.3861 & 0.0000 & & & & \\
\hline COSY & -0.7639 & -0.5791 & 0.3972 & 0.1964 & 0.7160 & 0.7036 & 1.0000 & & \\
& 0.0000 & 0.0010 & 0.0329 & 0.3073 & 0.0000 & 0.0000 & & & \\
\hline Angle 5 & -0.6136 & -0.3269 & 0.4804 & -0.1266 & 0.2617 & 0.5647 & 0.4260 & 1.0000 & \\
& 0.0004 & 0.0835 & 0.0083 & 0.5130 & 0.1702 & 0.0014 & 0.0212 & & \\
\hline Td & -0.9180 & -0.6687 & 0.6062 & 0.0167 & 0.7345 & 0.8053 & 0.6679 & 0.7257 & 1.0000 \\
& 0.0000 & 0.0001 & 0.0005 & 0.9316 & 0.000 & 0.000 & 0.0001 & 0.000 & \\
\hline
\end{tabular}


Linear regression with collinearity diagnostics showed colinearity existed within the co-relating factors. Dimension reduction using principal component analysis was applied after the variables were standardized ( $\mathrm{z}$ score).If more than $75 \%$ of the variance can be explained by several components (principal components ), it can be regarded as major factor. Principal component analysis showed that $79.06 \%$ of the total variance could be explained by three principal components (table 4). So three principal components (z1, z2, z3) were calculated and linear regression analysis was applied.

\section{$\mathrm{Z}$ score OT $=136.72-8.38(\mathrm{z1}) \mathbf{8 . 0 9}(\mathrm{z2}) \mathbf{1 1 . 2 7 ( z 3 )}$}

After operation the final equation could be obtained as

OT $=457.44+1.17$ (BMI) 2.13 (IA) -4.25 (IP) 9.43(IS) 4.77(IT) 0.64(COSY) +1.53(Angle5) 7.72 (Td)

\section{DISCUSSION:}

The operative time for resection of rectal cancer is influenced by a surgeon's skills ${ }^{[16,22],}$ patient's clinical and anatomical factors such as gender, BMI, distance of tumor from anal verge, pelvic size ${ }^{[23,24]}$ and different surgical procedure. Many pelvic parameters have been used to determine their predicting role on operative difficulty for sphincter preserving resection of rectal cancer. Results are still inconsistent regarding which pelvic parameter is the best predictor. Smaller pelvic outlet ${ }^{[14]}$ a less acutely curved sacrum, a narrow transverse intertuberous distance ${ }^{[10]}$ ,shorter pubic coccyx axis, ${ }^{[13]}$ or transverse interspinous distance ${ }^{[25]}$ and a smaller lower pelvic diameter ${ }^{[13]}$ related to longer operative time. Wang et al ${ }^{[26]}$ reported that interacetabular, anatomic transverse, interischial, intertuberous distance, distance between the coccyx and symphysis, the angles of the lower border of the symphysis pubis, upper border of symphysis pubis, and sacral promontory are inversely related to operative time. However, our study showed that IA (p 0.110) and COSY ( $p$ 0.674 ) were not statistically significant. The reason may be a small sample size. However in our study we find a significant relationship between interspinous [IS, $\mathrm{P}=0.004$ ] and intertuberous [IT, $\mathrm{P}=0.003$ ] diameters with operating time. These results were conforming with the results of study conducted by Salerno $\mathrm{G}$ et $\mathrm{al}^{[27]}$. The Akiyoshi group has previously published an excellent study identifying patient's factors predicting the difficulty of performing laparoscopic low anterior resection for rectal cancer ${ }^{[18]}$. In contrast, in our study all surgeries were performed by the same surgeon, instead of several as in Akiyoshi group. Sphincter preserving resection for rectal cancer $3-4 \mathrm{~cm}$ to anal verge has been associated with increased possibility of positive resection margin and a high chance of recurrence ${ }^{[28]}$ Our study includes patients with rectal cancer 4-12 cm from anal verge, whereas patients with rectal cancer 3-8 $\mathrm{cm}$ from anal verge are included in Akiyoshi's study. Consequently, both studies reveal that BMI, tumor distance to anal verge and pelvic anatomy are predictors for operative difficulty. Some authors have demonstrated significant differences in pelvic measurements between the sexes. ${ }^{[23,}{ }^{29]}$ But there is also considerable variation and overlap between the sexes ${ }^{[27]}$. Gender has previously been considered a factor in influencing operative difficulty. ${ }^{[13,30]}$ Qiken et al ${ }^{[31]}$ showed sex differences in factors impacting operative time. BMI (estimate $=0.11, \mathrm{P}=0.0035$ ), interspinous distance (estimate $=-0.04, \mathrm{P}=0.0010$ ), and preoperative chemoradiotherapy (estimate $=0.90$, $P=0.0011$ ), were significantly associated with the standardized operative time in males based on multivariate analysis . In females, prior abdominal surgery (estimate $=1.12, \quad P=0.0003$ ) and concurrent diseases (estimate $=0.81, P=0.0059$ ) were associated with the standardized operative time. However, Our study showed that operative time in males is longer than females because of narrow and deep pelvis in males. Greater mesorectal volume in patients with higher BMI restricts the operative field and increases operative time. The predicting role of BMI for laparoscopic sphincter preserving resection of rectal cancer has been observed in previous studies ${ }^{[13]}$; however, other researchers have shown that visceral fat may be a better predictor of operative difficulty than BMI ${ }^{[17]}$.Patient's obesity seemed to be a favorable factor for resectability of tumors located in the rectum when the surgical procedures were performed by surgeons with low case volume. ${ }^{[32]}$ Because the meso-rectum presents a considerable obstacle to the growth of cancers. ${ }^{[33]}$ Their explanation is the probably smaller volume of peri-rectal fatty tissue in lean patients than in obese counterparts. Small volume of peri-rectal fatty tissue can contribute to the early tumor infiltration of the pelvic wall and/or adjacent organs, which decreased the rate of resectability of rectal cancer and increase in operating time. Wepingchenet $\mathrm{el}^{[34]}$ study showed that BMI is a predictor of operative time for men only. The same result was observed in a previous study; however, no detailed data were presented. ${ }^{[14]}$ BMI does not consistently reflect body adipose tissue distribution. It has been observed that obese males have more visceral fat, whereas obese females have more subcutaneous fat. ${ }^{[35,36]}$ This different distribution of fat in males and females may explain that 
BMI is a predictor only for males. Our results show that BMI is a predictor for operative time in females .Relatively smaller male sample in our study may account for the above finding. However, we have found that BMI is an easily obtainable and useful parameter in predicting operative difficulty.

Distance from anal verge is also an important factor effecting operating time in resection of rectal cancer. More the distance from anal verge, more accessible the tumor, less difficulty in dissection and hence less is operating time. Qiken at $\mathrm{al}^{[31]}$ in their study showed that tumor distance from anal verge (estimate $=-0.17, P=0.0355$ ) is apredictor for standardized operative time. Our study showed similar result.

Based on the equation, BMI, angle 5, transverse diameters of the pelvis, Cosy, Gender and Distance of tumor from anal verge were related to operating time. However none of the factors was the dependent factor affecting operating time. Thus, the frame of the pelvis should be considered as a whole. BMI and angle 5 have positive effects on operating time, while transverse diameters (IA, IP, IS and IT) and CoSy have negative effects on OT. Besides the anatomical factors, BMI, which could reflect the soft tissue volume in the pelvis, was also very important in affecting operating time.This equation can be used as a very useful tool for preoperative assessment of patients undergoing LRC. If calculated or predicted operating time is more than a given time, the technique might not be suitable for junior specialists without extensive training. Further research should be performed to identify the given time.

The strength of our study is that we used three-dimensional measurements to obtain pelvimetry data, which is much more accurate than that of two-dimensional measurements. We described the relationship between factors and operating time more accurate by the equation, which provides the internal relationship among the factors. The small number of patients is the major limitation of the study. In addition, the timings for different steps of the procedure were not recorded, which lead to step-by-step analysis of the procedures impossible. We recognized the limitations, however we believe that this study provides important information for further research.

\section{CONCLUSION}

No specific demographic data and any measurement of pelvimetry could be identified as an independent predictor for operating time in our study. Instead, BMI, angle
5, distance of tumor from anal verge, transverse diameters of the pelvis except IA and COSY played the most important role in affecting operating time. The equation reveals the internal relationship among the factors, and it can be a very useful tool in preoperative assessment for predicting operative difficulty.

\section{REFERENCES}

1. American Cancer Society. Global Cancer Facts \& Figures 2nd Edition. Atlanta: American Cancer Society; 2011.

2. American Cancer Society. Cancer Facts \& Figures 2015. Atlanta: American Cancer Society; 2015.

3. Javid G, Zargar SA, Rather S, Khan AR, Khan BA, Yattoo GN et al ; Incidence of colorectal cancer in Kashmir valley, India.. Indian J Gastroenterol. 2011 Feb; 30(1):7-11.

4. Mir SA, Chowdri NA, Parray FQ, MirP, YasirB,Muntakhab N et al ; Sphincter-saving surgeries for rectal cancer: A single center study from Kashmir.South Asian J Cancer. 2013 Oct-Dec; 2(4): 227231 .

5. Nussbaum DP, Speicher PJ, Ganapathi AM, Englum $\mathrm{BR}$, Keenan JE, Mantyh CR, et al; Laparoscopic versus open low anterior resection for rectal cancer: results from the national cancer data base. Journal of gastrointestinal surgery: official journal of the Society for Surgery of the Alimentary Tract. 2015;19(1):12431;

6. Lacy AM, Garcia-Valdecasas JC, Delgado S, Castells A, Taura P, Pique JM, et al; Laparoscopy-assisted colectomy versus open colectomy for treatment of non-metastatic colon cancer: a randomised trial. Lancet. 2002; 359(9325):22249.

7. Anderson C, Uman G, Pigazzi A: Oncologic outcomes of laparoscopic surgery for rectal cancer: a systematic review and meta-analysis of the literature.Eur $J$ SurgOncol 2008, 34:1135-1142.

8. Leung KL, Kwok SP, Lam SC, Lee JF, Yiu RY, Ng SS, et al; Laparoscopic resection of rectosigmoid carcinoma: prospective randomised trial. Lancet. 2004; 363(9416):118792.

9. Laurent C, Leblanc F, Wutrich P, SchefflerM,Rullier E .Laparoscopic versus open surgery for rectal cancer: long-term oncologic results.AnnSurg 2009, 250:54-61.

10. Killeen T, Banerjee S, Vijay V, Al-Dabbagh Z, Francis 
$\mathrm{D}$, Warren $\mathrm{S}$ et al. Magnetic resonance (MR) pelvimetry as a predictor of difficulty in laparoscopic operations for rectal cancer.SurgEndosc 2010, 24:2974-2979.

11. Veenhof AA, Engel AF, van der Peet DL, Sietses C, Meijerink WJ, de Lange-de Klerk ES, etal.Technical difficulty grade score for the laparoscopic approach of rectal cancer: a single institution pilot study.Int $J$ Colorectal Dis 2008, 23:469-475.

12. Akagi $\mathrm{T}$, Inomata $\mathrm{M}$, Etoh $\mathrm{T}$, Moriyama $\mathrm{H}$, Yasuda $\mathrm{K}$,Shiraishi $\mathrm{N}$ et al :Multivariate evaluation of the technical difficulties in performing laparoscopic a $\mathrm{nterior}$ resection for rectal cancer.SurgLaparoscEndoscPercutan Tech 2012, 22:52-57.

13. Targarona EM, Balague C, Pernas JC, Martinez $\mathrm{C}$,Berindoague $\mathrm{R}$, Gichl et al : Can we predict immediate outcome after laparoscopic rectal surgery? Multivariate analysis of clinical, anatomic, and pathologic features after 3-dimensional reconstruction of the pelvic anatomy.AnnSurg 2008, 247:642-649.

14. Akiyoshi T, Kuroyanagi H, Oya M, Konishi T, Fukuda M, Fujimoto Y, et al; Factors affecting the difficulty of laparoscopic total mesorectal excision with double stapling technique anastomosis for low rectal cancer:Surgery 2009, 146:483-489.

15. Ishihara $\mathrm{S}$, Watanabe $\mathrm{T}$, Fukushima $\mathrm{Y}$, Akahane $\mathrm{T}$, Horiuchi A, Shimada R, etal.Safety and factors contributing to the difficulty of laparoscopic surgery for rectal cancer treated with preoperative chemoradiotherapy. Techniques in coloproctology. 2014; 18(3):24755.

16. Ogiso S, Yamaguchi T, Hata H, Fukuda M, Ikai I, Yamato T, et al. Evaluation of factors affecting the difficulty of laparoscopic anterior resection for rectal cancer: "narrow pelvis" is not a contraindication.SurgEndosc 19071912, 2011:25.

17. Seki Y, Ohue M, Sekimoto M, Takiguchi S, Takemasa I, Ikeda M, et al. Evaluation of the technical difficulty performing laparoscopic resection of a rectosigmoid carcinoma: visceral fat reflects technical difficulty more accurately than body mass index.SurgEndosc 2007, 21:929-934.

18. Killeen T, Banerjee S, Vijay V, Al-Dabbagh Z, Francis $\mathrm{D}$, WarranS,et al. Pelvic dimensions as a predictor of difficulty in laparoscopic surgery for rectal cancer:
SurgEndosc 2012, 26:277.

19. Akiyoshi T, Watanabe T, Ueno M. Pelvic dimensions as a predictor of difficulty in laparoscopic surgery for rectal cancer: SurgEndosc 2011, 25:3122-3123.

20. Poon J T C and Law W L. Laparoscopic resection for rectal cancer: a review," Annals of Surgical Oncology 2009, 16(11): 30383047.

21. Xiaocong $\mathrm{Z}$, Meng $\mathrm{Su}$; Keqiong $\mathrm{Hu}$, Yinfa $\mathrm{Su}$, YinghaiYe, Chongkuan $\mathrm{H}$, et al.Applications of computed tomography pelvimetry and clinicalpathological parameters in sphincter preservation of mid-low rectal cancer.Int J ClinExp Med. 2015; 8(2): 21742181..

22. Ogiso S1, Yamaguchi T, Hata H, Kuroyanagi H, Sakai Y. "Introduction of laparoscopic low anterior resection for rectal cancer early during residency: a single institutional study on short-term outcomes. SurgEndosc. 2010 Nov; 24(11):2822-9.

23. Boyle KM, Petty D, Chalmers AG, Quirke P, Cairns A, Finan PJ, et al.MRI assessment of the bony pelvis may help predict resectability of rectal cancer. Colorectal Dis.2005;7:232240.

24. Salerno G, Daniels IR, Brown G, Norman AR, Moran $\mathrm{BJ}$, Heald RJ, et al. Variations in pelvic dimensions do not predict the risk of circumferential resection margin (CRM) involvement in rectal cancer. World J Surg. 2007;31:13131320

25. Baik SH, Kim NK, Lee KY, Sohn SK, Cho CH, Kim MJ, et al. Factors influencing pathologic results after total mesorectal excision for rectal cancer: analysis of consecutive 100 cases: Ann SurgOncol. 2008 Mar;15(3):721-8.

26. Wang chu, Xiao Yi, Qiu H, Yao J, Pan w, et al.“Factors affecting operating time in laparoscopic anterior resection of rectal cancer. World J SurgOnc 2014 (12); 44:1477-7819.

27. Salerno G, Daniels IR, Brown G, Heald RJ, Moran BJ, et al. Magnetic resonance imaging pelvimetry in $\mathbf{1 8 6}$ patients with rectal cancer confirms an overlap in pelvic size between males and females: Colorectal Dis. 2006; 8:772776.

28. Gu J, Bo XF, Xiong CY, Wu AW, Zhang XP, Li M, et al.Defining pelvic factors in sphincter-preservation of low rectal cancer with a three-dimensional digital model of pelvis:Dis Colon Rectum 2006, 49:1517- 
1526.

29. Verschueren RC, Mulder NH, Van Loon AJ, De Ruiter AJ, Szabo BG.The anatomical substrate for a difference in surgical approach to rectal cancer in male and female patients.Anticancer Res. 1997;17:637641.

30. Law WL, Chu KW. Anterior Resection for Rectal Cancer withMesorectal Excision: A Prospective Evaluation of 622 Patients, Annals of Surgery: August 2004; 240 (2): 260-268.

31. Qiken L, Dechuan L, Lai J, Qiu P, Fu Z, Tang L, et al; Factors Influencing Difficulty of Laparoscopic Abdominoperineal Resection for Ultra-Low Rectal Cancer:Surgical Laparoscopy, Endoscopy \& Percutaneous Techniques: April 2017 ;27 ( 2): 104109.

32. Görög D, Tóth A, Péter A, Perner F. Is obesity a favorable factor for resectability of rectal cancer? Hepatogastroenterology. 2004; 51:630633.

33. Heald RJ, Karanjia ND. Results of radical surgery for rectal cancer. World J Surg.1992; 16:848857.

34. Chen w, Li Q, Fan Y, Li D, Jiang L, Qiu,P et al; Factors Predicting Difficulty of Laparoscopic Low Anterior Resection for Rectal Cancer with Total Mesorectal Excision and Double Stapling Technique Published: March 18,201610.1371/journal.pone.0151773.
35. Havel PJ, Kasim-Karakas S, Dubuc GR, Mueller W, PhinneySD.Gender differences in plasma leptin concentrations. Nature medicine. 1996; 2(9):94950.

36. Kotani K, Tokunaga K, Fujioka S, Kobatake T, Keno Y, Yoshida $\mathrm{S}$, et al.Sexual dimorphism of age-related changes in whole-body fat distribution in the obese. International journal of obesity and related metabolic disorders: journal of the International Association for the Study of Obesity. 1994; 18(4):2072 